\title{
Antibacterial Response
}

National Cancer Institute

\section{Source}

National Cancer Institute. Antibacterial Response. NCI Thesaurus. Code C26012.

An Antibacterial Response is an induced humoral or cell-mediated reaction of the immune system to a bacterial antigen or infection. 